\title{
What is your diagnosis?
}

A 32-year-old patient who was G9 P6 Y6 A2 was admitted to our clinic for detailed examination at the 21 st week of gestation. Her medical history revealed that there was no antenatal follow-up. Abdominal sonographic examination showed one live fetus at 20 weeks of development.
Detailed ultrasonographic examination revealed a $2 \times 2 \mathrm{~cm}$ cystic enlargement localized in the fetal posterior fontanelle (Figure 1). Magnetic resonance imaging (MRI) was performed after the ultrasonography (Figure 2). What is your diagnosis?
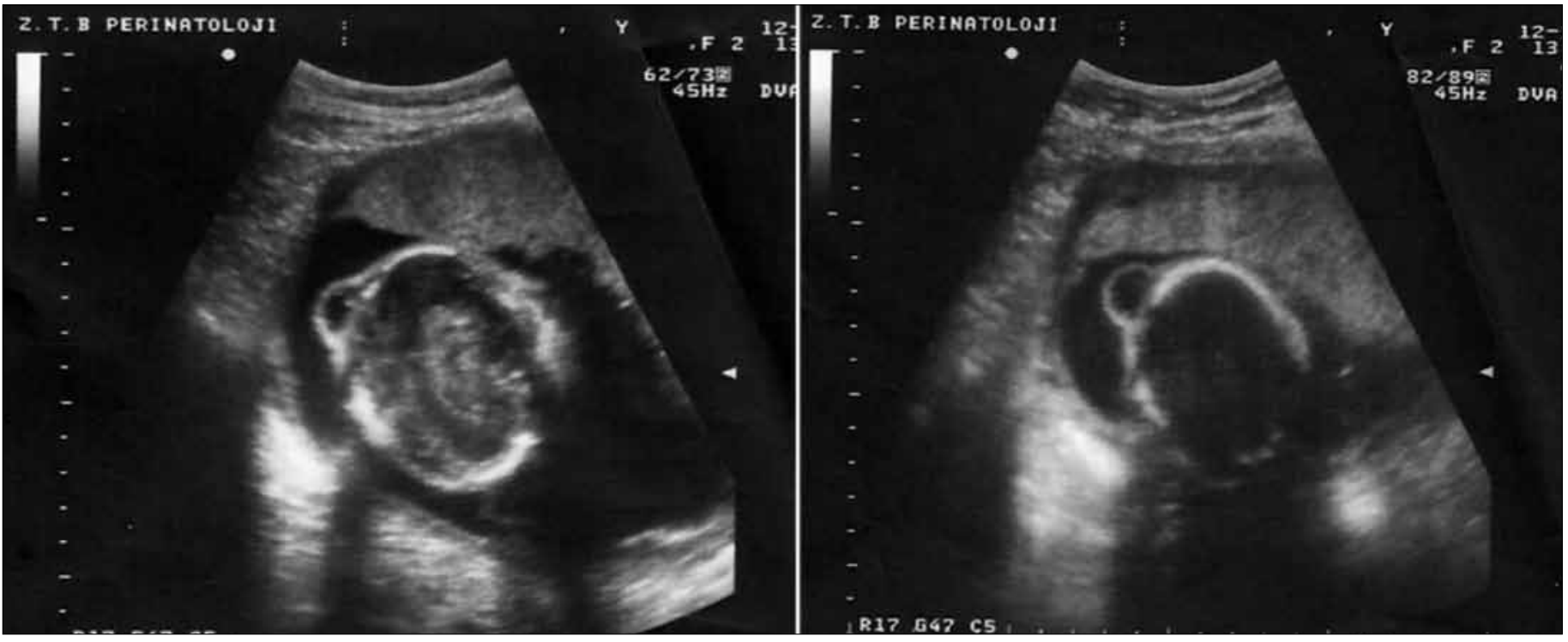

Figure 1. Fetal cranial ultrasonogram
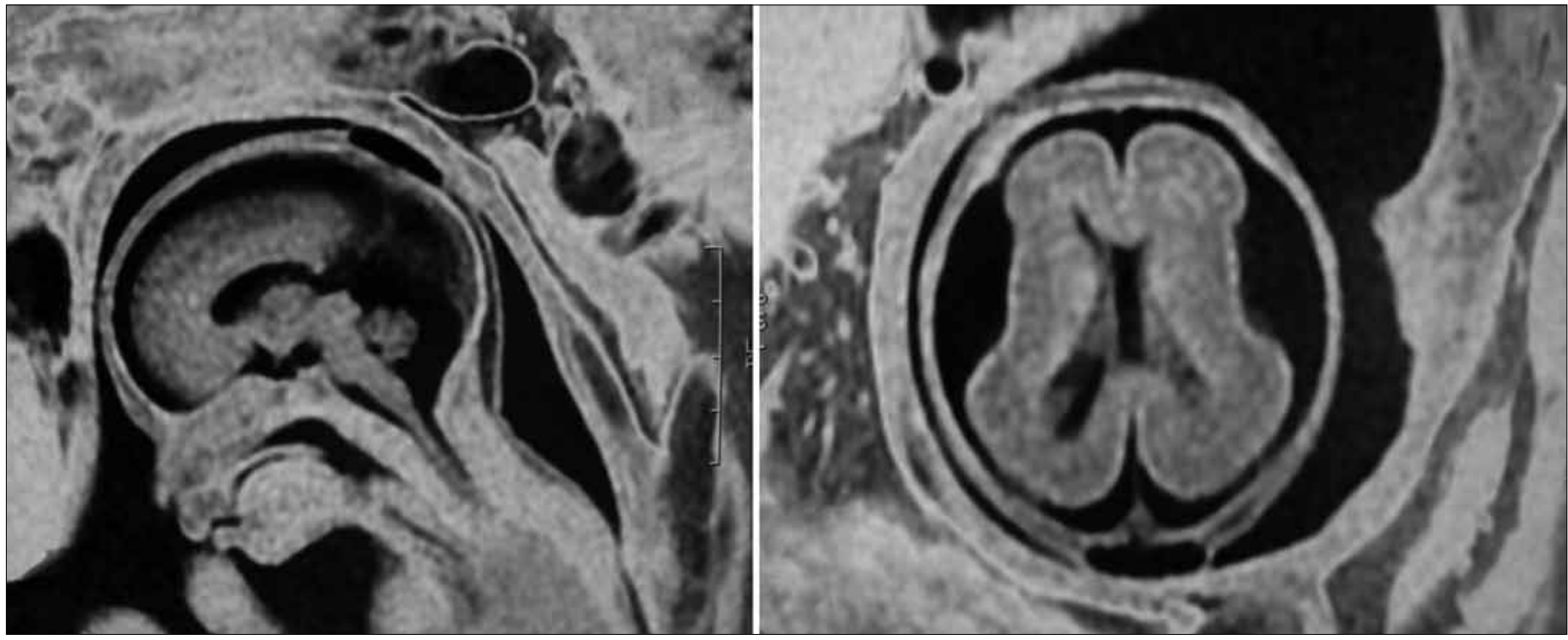

Figure 2. Fetal cranial MRI 


\section{Answer}

This case shows the importance of fetal MRI in prenatal diagnosis. With only sonographic examination, the most probable diagnosis was encephalocele. But, with the addition of MRI, the diagnosis of this case changed. The lesion was localized under the skin and there was no relationship with intracranial structures. A cystic lesion was found in the parieto-occipital region with a size of $2 \times 1 \times 5 \times 1 \mathrm{~cm}$ had a hypodense appearance on T1 and a hyperdense appearance on T2 (Figure 2). Intracranial structures were normal on MRI. With all these findings, the lesion was determined to be a subcutaneous epidermal cyst. The family was informed and it was decided to continue the pregnancy. However, the patient was lost to follow-up.

The use of fetal MRI was first reported in 1983 (1). Since then, with rapidly increasing technological developments and accumulated knowledge and experience, MRI is predominantly used for central nervous, respiratory and gastrointestinal anomalies because of the limitations of ultrasonography. MRI is not recommended in the first trimester due to a lack of sufficient information about its safety (2).

Encephalocele is an extremely rare neural tube defect. The incidence of encephalocele is $0.8-5 / 10,000$ live births (3). Although the mechanism of encephalocele is not completely known, an anterior neural tube closure defect is the most likely mechanism (3). As a result of this fetal defect, changes occur to the calvarium and dura mater, along with herniation of the leptomeninges to the extracranial region. This sac sometimes consists of only cerebrospinal fluid and sometimes cerebrospinal fluid and brain tissue. It can appear in the occipital, frontal and basal regions. The localization of herniation is associated with a racial distribution. The occipital localization of encephalocele is the most recognizable type during the antenatal period. Because of the localization and appearance of the cyst, our initial diagnosis was encephalocele. However, MRI was also used for a differential diagnosis and with this method we could provide sufficient information to the family. Obesity and oligohydramniosis have negative effects on ultrasonographic images, but these conditions have no negative effects on MRI. On the other hand, MRI has some limitations, like excessive fetal movement and fetal position changes. Today, images are obtained using an ultra-fast image capture technique (4). Before the procedure, an empty stomach and an empty bladder are recommended. Imaging is often performed in the supine position, but in later weeks of pregnancy, imaging is performed in the left lateral position because of supine hypotension.

Our case demonstrates once again that for soft tissue imaging, MRI is specific and sensitive. Our case also shows that T2 imaging is best for soft tissue while T1 imaging is more sensitive for hemorrhage, adipose tissue and diaphragmatic hernia.

\section{Oktay Kaymak, Ayla Aktulay Onat, Ayşe Kırbaş, Cantekin İskender, Nuri Danışman \\ High Risk Pregnancy Unit, Dr. Zekai Tahir Burak Training and Research Hospital, Ankara, Turkey}

\section{References}

1. Blondin D, Turowski B, Schaper J. Fetal MRI. 2007; 179: 111-8.

2. Sohn YS, Kim MJ, Kwon JY, Kim YH, Park YW. The usefulness of fetal MRI for prenatal diagnosis. Yonsei Med J 2007; 48: 671-7. [CrossRef]

3. Quinn TM, Hubbard AM, Adzick NS. Prenatal magnetic resonance imaging enhances fetal diagnosis. J Pediatr Surg 1998; 33: 553-8. [CrossRef]

4. Mirsky DM, Shekdar KV, Bilaniuk LT. Fetal MRI: head and neck. Magn Reson Imaging Clin N Am 2012; 20: 605-18. [CrossRef]

\section{ADVISORY BOARD OF THIS ISSUE (September 2013)}

Aysel Derbent
Barış Ata
Başar Tekin
Begüm Aydoğan
Candan İltemir Duvan
Cem Çelik

Aysel Derbent

Barış Ata

Başar Tekin

Candan İlemir Duvan

Cem Çelik
Çetin Çelik

Ebru Öztürk

Eralp Başer

Esma Sarkaya

Hasan Kafalı

İsmet Gün
Mert Göl

Mete Gürol Uğur

Özlem Moraloğlu

Polat Dursun

Remzi Abalı

Sefa Kelekçi
Serdar Dilbaz

Yasemin Taşçı

Yusuf Üstün 